\title{
Molecular Diagnostic Method
}

National Cancer Institute

\section{Source}

National Cancer Institute. Molecular Diagnostic Method. NCI Thesaurus. Code C18194.

Methods for diagnosis or monitoring of disease predisposition by translation and

validation of molecular discoveries in medicine into the clinical diagnostic setting. 